\title{
Alcohol Stress Response Dampening during imminent vs. distal, uncertain threat
}

\author{
Kathryn R. Hefner, Christine A. Moberg, Laura Y. Hachiya, and John J. Curtin \\ ${ }^{1}$ Department of Psychology, University of Wisconsin-Madison, Madison, WI USA
}

\begin{abstract}
Research indicates that fear and anxiety are distinct processes with separable neurobiological substrates. Predictable vs. unpredictable shock administration has been used to elicit fear vs. anxiety, respectively. Recent research has demonstrated that alcohol may reduce anxiety but not fear. However, previous manipulations of predictability have varied both probability and temporal uncertainty of shock threat, leaving unresolved questions regarding which stimulus characteristics elicit anxiety and are sensitive to alcohol stress response dampening (SRD). We developed a novel paradigm to closely parallel basic research in animals that systematically varied temporal uncertainty of threat while holding threat probability constant. Intoxicated ( $0.08 \%$ target BAC), placebo, and no-alcohol control participants viewed a series of visual threat cues. Certain cue duration ( 5 seconds) blocks were equivalent to predictable shock blocks eliciting fear in earlier research. Uncertain cue duration $(5,20,50$ or 80 second, intermixed) blocks introduced temporal uncertainty regarding impending shock to elicit anxiety. Startle potentiation relative to matched cue periods in no-shock blocks provided the primary measure of affective response. All threat cues produced robust startle potentiation. Alcohol reduced startle potentiation during the first 5 seconds of threat cue presentation in uncertain but not certain duration blocks. Alcohol also reduced startle potentiation at later times among longer uncertain duration cues, suggesting that alcohol SRD persisted. Trait negative emotionality and binge drinking status moderated alcohol SRD magnitude during uncertain threat. These translational findings corroborate previous reports regarding distinct substrates of fear vs. anxiety, and have implications for both alcoholism etiology and comorbidity with anxiety disorders.
\end{abstract}

\section{Keywords}

stress-response dampening; alcohol; anxiety; uncertain threat; startle response

\section{Introduction}

The Stress Response Dampening (SRD) model suggests that alcohol intoxication reduces negative affective response to aversive stimuli, and that this affective negative reinforcement motivates continued recreational and disordered alcohol use (Sher, 1987). Furthermore, individuals who report SRD as an important motive for their alcohol use display increased 
risk for alcohol use disorders (Cooper et al., 1995; Schroder \& Perrine, 2007). High rates of alcohol use, abuse, and dependence are observed in patients with a subset of anxiety disorders including generalized anxiety disorder, post-traumatic stress disorder and panic disorder (Grant et al., 2006; Kessler, 1995). Stressors have been long recognized as a potent instigators of relapse among abstinent alcoholics (Brown, Vik, Patterson, Grant, \& Schuckit, 1995; Sinha, 2001; Sinha et al., 2011), and stress-induced reinstatement of alcohol use is consistently observed in animal models (Lê et al., 1998; Overstreet et al., 2007 ). Finally, neuroadaptive changes in the stress response following chronic alcohol SRD has been implicated in alcoholism etiology (Breese, Sinha, \& Heilig, 2011; Koob \& LeMoal, 2008; Koob \& Volkow, 2010; Shaham \& Hope, 2005; Volkow \& Li, 2005; Weiss, 2001). For all of these reasons, clarifying the contexts where alcohol SRD is observed and the mechanism(s) involved in this effect remain important clinically relevant questions. Alcohol SRD research offers the potential to advance understanding of etiological mechanisms in alcoholism, to identify pre-morbid risk factors, and to aid development of behavioral and pharmacological treatments for alcoholism.

Unfortunately, the "stress response" remains ill-defined and inconsistently operationalized in research on alcohol SRD. Basic research on the stress response implicates central nervous system (CNS), endocrine, and peripheral biological systems that produce changes in affect, arousal, and attention (McEwen, 2001; McEwen, Eiland, Hunter, \& Miller, 2012; Sapolsky, 2002, 2003). Research is rapidly accruing to suggest that the CNS negative affect component of the stress response, and more specifically, anxiety during a subset of stressors characterized by threat uncertainty, may provide a critical mechanism to account for alcohol's reinforcing SRD properties (Hefner \& Curtin, 2012; Moberg \& Curtin, 2009).

Recent development of manipulations and measures in affective neuroscience research with humans and animal models now provides the precision to parse potentially distinct forms of negative affect (e.g., fear vs. anxiety). These advances provide a foundation for programmatic manipulations of threat uncertainty to delineate mechanisms and boundary conditions for alcohol SRD. The research in this report focuses specifically on temporal threat uncertainty (imminent vs. uncertain/distal threat), which remains understudied, but strongly implicated in basic science and clinical literatures on anxiety (Blanchard \& Blanchard, 2008; Sarinopoulos et al., 2010).

\section{Threat uncertainty, fear, anxiety, and the startle response}

Research in affective neuroscience has relied extensively on cued threat tasks to explicate psychological and neurobiological mechanisms involved in the negative affective response to stressors in animals and humans (Davis, Walker, Miles, \& Grillon, 2010; Delgado, Olsson, \& Phelps, 2006; LeDoux, 1998; Phelps, 2006; Phelps \& LeDoux, 2005). Much of the affective neuroscience research employing cued threat of shock tasks has relied on startle potentiation as the primary measure of defensive system activation in response to threat (Grillon, 2008). The use of startle potentiation to index affective response to threat among rodents, non-human primates, and humans has provided an important animal-human translational bridge in this research (Davis, 2006; Davis, Antoniadis, Amaral, \& Winslow, 2008; Davis et al., 2010). Programmatic research that measures startle reflex potentiation during cues that were contingently paired with shock (100\% cue-contingent shock) has 
provided clear evidence that the central nucleus of the amygdala $(\mathrm{CeA})$ mediates defensive system activity during unambiguous, high probable, imminent threat (Davis, 2006).

Systematic measurement of startle potentiation during these certain threats (e.g., 100\% cuecontingent/predictable shock) in rodents, non-human primates, and humans has provided an important animal-human translational bridge to study fear.

Additional manipulations that potentiate the startle reflex have been identified. Bright light, temporally uncertain shock, and infusions of the anxiogenic peptide corticotropin-releasing factor (CRF) potentiate startle in rats (Liang et al., 1992; Swerdlow, Geyer, Vale, \& Koob, 1986; Walker \& Davis, 1997a; Walker, Miles, \& Davis, 2009). In humans, darkness and unpredictable/non-contingent shock have been shown to potentiate startle (Grillon, Baas, Lissek, Smith, \& Milstein, 2004; Grillon, Pellowski, Merikangas, \& Davis, 1997). These threats are more ambiguous or otherwise uncertain relative to $100 \%$ cue-contingent shock; such uncertain threats produce more sustained rather than phasic startle potentiation in both humans and animals. Basic neuroscience research in animals indicates that CRF and norepinephrine (NE) sensitive pathways through the lateral divisions of the $\mathrm{CeA}$ and the bed nucleus of the stria terminalis (BNST) appear to be involved in startle potentiation to uncertain threats. Indeed, affective neuroscientists suggest that startle potentiation to uncertain threats provide valuable laboratory models to study anxiety (Davis et al., 2010; Grillon, 2008).

\section{Alcohol SRD during uncertain threat}

Previous research from our laboratory has indicated that alcohol does not reduce startle potentiation during well-defined, unambiguous, high probability, attentionally focal certain threats (Curtin et al., 1998; Curtin et al., 2001; Moberg \& Curtin, 2009; Hefner \& Curtin, 2012). However, available evidence suggests that alcohol SRD may be observed more selectively during uncertain threats. Moberg \& Curtin (2009) provided preliminary support for this thesis using the No Shock, Predictable Shock, Unpredictable shock (NPU) task developed by Grillon and colleagues (Grillon et al., 2004) to parse anxiety from fear using unpredictable (i.e., non-contingent) vs. predictable shock administration (i.e., $100 \%$ cue contingent). Specifically, a moderate alcohol dose (target BAC of $0.08 \%$ ) selectively reduced startle potentiation during uncertain threat cues in unpredictable shock blocks where shocks were administered non-contingently during both cues and the periods between these cues. In contrast, alcohol did not affect startle potentiation during certain threat cues in predictable shock blocks where shocks were contingently administered at the end of these 6 second cues. This study provided important, preliminary evidence of selective alcohol SRD on anxiety during uncertain threat but not fear during certain threat in humans. However, this coarse manipulation of shock predictability confounded the probability and temporal precision of shocks across predictable and unpredictable blocks. Specifically, shock administration was highly probably (100\%), temporally precise, and imminent (5.5 s after cue onset) during cues in predictable blocks. In contrast, the probability of shock during cues was low (20\%) and there was a high degree of temporal uncertainty regarding when these shocks would be administered during unpredictable blocks. This left important questions unanswered regarding the threat characteristics that are necessary and/or sufficient to elicit anxiety vs. fear and to observe alcohol SRD. 
To address these limitations, Hefner \& Curtin (2012) developed a novel task that selectively manipulated shock probability during threat cues while holding the temporal precision of shock administration constant. Specifically, shock probability was parametrically manipulated (100\%, $60 \%$ or $20 \%$ of the cues) across separate blocks of trials. In all blocks, shock administration was temporally precise ( $4.5 \mathrm{~s}$ post cue onset during $5 \mathrm{~s}$ cues). Anxiety was expected to increase when threat occurrence was uncertain (i.e., 20\% and 60\% shock probability). Further, alcohol SRD was expected only during uncertain as opposed to certain (i.e., $100 \%$ shock probability) threat. Consistent with this, the magnitude of alcohol SRD indexed by startle potentiation was significantly greater during both $20 \%$ and $60 \%$ uncertain threat conditions relative to $100 \%$ certain threat. These results indicate that manipulating threat probability alone is sufficient to moderate the magnitude of alcohol SRD with robust SRD observed during low probability threat.

\section{Temporal uncertainty, anxiety, and the current study}

At least two interpretations of Moberg \& Curtin (2009) and Hefner \& Curtin (2012) are viable. Alcohol SRD may be observed narrowly during low probability threats given that shocks were administered at lower probabilities during uncertain threat cues than certain threat cues in both experiments. Alternatively, both unpredictable shock administration and low probability shock administration may be distinct manipulations of a broader threat uncertainty construct. If true, alcohol SRD should be observed during other manipulations of threat uncertainty where certain and uncertain threat conditions do not differ in shock probability. We designed the manipulation of temporal threat uncertainty used in this report to test these two competing interpretations.

Anxiety and fear are theorized to differ with respect to the time-course of these two distinct responses to threats (Grillon, 2008). We should observe sustained startle potentiation during longer duration uncertain threat cues if the subjective emotional response during uncertain threat is best characterized by anxiety (vs. fear during certain threat). Furthermore, alcohol SRD should be observed throughout this sustained period of uncertain threat. A second primary goal of the experiment in this report was to test these predictions about alcohol SRD on sustained startle potentiation during longer duration uncertain threat cues.

A third primary goal of the experiment in this report was to design an animal-to-human translational task to bridge emerging evidence on mechanisms involved in response to uncertain threat. Davis, Walker, and colleagues have examined the neural mechanisms that mediate startle potentiation during temporally uncertain vs. certain, imminent threat in rodents in a programmatic series of elegant studies (Campeau \& Davis, 1995; Davis et al., 2010; Hitchcock \& Davis, 1987; Miles, Davis, \& Walker, 2011; Walker \& Davis, 1997a, 1997b, 2008). Across these studies, they examine temporally uncertain shock threat produced by variable duration $(3 \mathrm{~s}-8 \mathrm{~min}$ ) cues that co-terminate in shock or fully unpredictable shocks administered at any point during long duration $(8 \mathrm{~min})$ cues. They contrast these temporally uncertain threats with certain, imminent threats produced by short, fixed duration (e.g., $3.2 \mathrm{~s}$ ) cues that co-terminate with shock. Following closely from Davis and Walker's procedures with rodents, we developed a novel task to vary systematically the temporal precision with which participants could predict electric shock administration from 
threat cues while holding constant the probability of shock administration and other important characteristics of these cues (e.g., perceptual demands, assessment time). Certain threat cues indicated temporally precise, imminent ( 5 seconds post cue onset) administration of electric shock. Uncertain threat cues indicated temporally uncertain (5 seconds to 3 minutes post cue onset) shock administration. As per Davis \& Walker, we measured negative affective response during threat cues via startle potentiation in both intoxicated and sober (placebo and true no-alcohol) control participants. Synthesis of previous rodent research using temporally uncertain vs. imminent threat with our preliminary findings regarding selective alcohol SRD during uncertain but not certain threat yielded the following two predictions:

1. Alcohol would selectively reduce startle potentiation measured immediately following threat cue presentation (4.5 seconds post cue onset) during temporally uncertain but not certain, imminent threat.

2. This alcohol SRD during uncertain threat would persist throughout the duration of the uncertain threat cues.

Examination of individual difference moderators (e.g., trait negative emotionality, measures of alcohol use and problems) of alcohol SRD was an important secondary goal given that these individual differences may represent important risk variables for alcohol use disorders. Covariation of alcohol SRD magnitude by these risk variables would provide additional evidence regarding the clinical relevance of alcohol SRD.

\section{Method}

\section{Participants}

Seventy-two University of Wisconsin-Madison undergraduate participants (36 female) were recruited using flyers and online advertisements. Participants were required to be between 21-35 years of age and to report recent experience with the dose of alcohol that would be administered in the study (i.e., at least 3 drinks for males and 2 drinks for females in a single episode of drinking within the last year). Participants were excluded if they reported a history of significant alcohol-related problems (e.g., DWI or other alcohol-related legal issue, hospitalization for excessive alcohol use and/or withdrawal; sanctioned at school or work for alcohol use), history of treatment for alcohol problems, history of attempts to limit alcohol use due to a perceived problem with alcohol, or a medical condition for which alcohol use was contraindicated. Participants were also excluded if they reported receiving psychotherapy or psychotropic medication within the past 6 months for any Axis I disorder. These selection criteria were necessary to assure safe administration of alcohol to research participants. Despite these safety criteria, our sample included substantive variability in alcohol use patterns and did report less severe alcohol related problems (e.g., missing class due to drinking or having a hangover; see alcohol use and problems measures in Table 1). Eligible participants were scheduled for an experimental session and told to abstain from alcohol use for 24 hours, and all food and beverages, other than water, for four hours prior to their experimental session. Participants were compensated \$15/hour for their time. 


\section{General Procedure}

Consent and screening-Preliminary study eligibility was determined during a phone screening session prior to admittance in the study. Upon arrival at the lab, participants provided proof of age and signed a consent form approved by the University of WisconsinMadison IRB. All participants completed a medical screening questionnaire at this time to verify their report regarding alcohol use, alcohol problems, and history of psychiatric and medical treatment from their previous phone screening. Female participants were administered an in-stream pregnancy test (Northwest Andrology \& Cryobank, Inc., Spokane, WA), with a negative result required for participation. A pre-experiment blood alcohol concentration (BAC) of $0.00 \%$ was verified via breathalyzer (Alcosensor IV; Intoximeters Inc., St. Louis, MO).

Baseline task-Prior to consuming study beverages, participants completed a baseline procedure to assess their mean startle response magnitude. This baseline startle response magnitude was obtained to use as a covariate to control for individual differences in startle response magnitude. In this baseline session, participants viewed a series of ten colored squares presented on a computer monitor. Each square was presented for 5 seconds with a variable inter-trial interval (ITI; range 7-11.5 s). Mean baseline startle response was calculated in response to 6 startle-eliciting noise probes (see Eyeblink startle response magnitude measurement for additional detail).

Beverage manipulation-Participants were randomly assigned to no-alcohol, placebo, or alcohol beverage groups (12 males and 12 females in each group). Participants in placebo and alcohol beverage group assignments were informed that they had been assigned to the alcohol group and would receive a moderately impairing dose of alcohol. This dose would be equivalent to 3-4 drinks in 1 hour for a $160-1 b$ person. Participants assigned to the alcohol group received two equal sized beverages consisting of fruit juice mixed with 100 proof vodka in a 3:1 juice to vodka ratio measured to produce a peak BAC of $0.08 \%$. Participants assigned to the placebo group received two equal sized beverages consisting of fruit juice and water poured from a clean vodka bottle in their presence (see Curtin \& Fairchild, 2003 for a description of the dosing formula and placebo-related procedures) ${ }^{\mathrm{i}}$. Participants in the no-alcohol beverage group were told that they would not be consuming alcohol and were given two equal sized beverages consisting of only fruit juice. For participants in all beverage conditions, each drink was consumed in 15 minutes for a total drinking time of 30 minutes. The experimental session began after a 25 minute post-drinking absorption period. Participants' BACs were measured just prior to the beginning and immediately following completion of the main task.

\footnotetext{
${ }^{\mathrm{i}}$ To verify the success of our placebo manipulation, we compared the alcohol and placebo groups on self-reported standard alcoholic drinks they believed they had consumed during the experiment. Participants in the alcohol group reported that their beverages contained significantly more alcohol $(\mathrm{M}=3.5$ drinks, $\mathrm{SD}=1.2$ drinks, Range $=1.0-6.0$ drinks $)$ than placebo participants $(\mathrm{M}=2.1$ drinks, $\mathrm{SD}=1.1$ drinks, Range $=0.0-4.0$ drinks), $\mathrm{t}(46)=4.1, \mathrm{p}<.001$. However, perceived alcohol content was significantly above 0 in both beverage groups (p's <.001 for one sample t-tests in each beverage group). Thus, the expectation of alcohol consumption was successfully established among participants in both the alcohol and placebo groups. However, as is typical with these manipulations, we were not entirely successful in matching level of expectations regarding consumption across the beverage groups.
} 
Shock tolerance threshold assessment-Following the beverage group manipulation, participants reported their subjective response to a series of increasing intensity $200 \mathrm{~ms}$ duration electric shocks ranging from just perceptible to a maximum of 7 $\mathrm{mA}$ to assess their maximum tolerance threshold per standardized procedures in our laboratory (e.g., Curtin et al., 2001; Hogle \& Curtin, 2006; Hogle, Kaye, \& Curtin, 2010). The series was terminated when participants reported that they had reached the highest shock level they could tolerate for the experiment. Shocks were administered across the distal phalanges of the index and ring fingers of left hand. Shock intensity during the main task was set to each participant's subjective maximum tolerance threshold to minimize individual differences in sensitivity and possible analgesic effects associated with alcohol.

Main task-Participants completed eight blocks of trials in the main task. In each block, participants viewed a series of colored square cues. These cues were presented in one of four block types: Certain Duration Shock blocks, Certain Duration No-shock blocks, Uncertain Duration Shock blocks, and Uncertain Duration No-shock blocks. Participants were instructed about the specific cue-shock contingencies in each block prior to the start of the task. The use of shock contingency instruction follows from standardized procedures in similar tasks (Grillon et al. 2004; Hefner \& Curtin, 2012; Moberg \& Curtin, 2009; Schmitz \& Grillon, 2012), and the focus of SRD theory on the expression of threat responding rather than acquisition or other earlier learning processes. Participants completed two blocks of each block type in one of eight between-subjects counterbalanced block orders. A message indicating block type was presented on the monitor at the onset of each block. The color of the square cues varied across the four block types to reinforce block type condition. The entire procedure required approximately 30 minutes to complete.

In the Certain Duration Shock blocks, participants were instructed that the duration of all cues was 5 seconds, separated by variable inter-trial intervals (ITI; range: 10-20 s). They were instructed that each cue would co-terminate with an electric shock (4.75 s post-cue onset) and that no shocks would be administered at any other time. Therefore shock administration was temporally certain and imminent following cue onset in these blocks. A total of 10 certain duration cues were presented across two blocks.

In Uncertain Duration Shock blocks, participants were instructed the duration of cues would vary from 5 seconds to 3 minutes, separated by a variable ITI (range: 10-20 s). In fact, four discrete cue durations were used $(5,20,50$, and $80 \mathrm{~s})$. They were instructed that each cue would co-terminate with an electric shock administered 0.25 seconds prior to cue offset. Therefore, shock administration was temporally uncertain and possibly distal following cue onset in these blocks. A total of 12 uncertain duration cues ( $3 \mathrm{x}$ per duration) were presented across two blocks

Four blocks (2x each) of matched Certain and Uncertain Duration No-shock blocks were included. All parameters (e.g., number of cues, cue duration) were identical to their respective, matched shock blocks. However, participants were instructed that no shocks would be administered at any time during these no-shock blocks. The no-shock blocks were included as a non-aversive control condition from which to calculate startle potentiation during cues in uncertain and certain duration blocks. 
Individual difference measures, debriefing, and release-After completing the main task, participants provided information on their drinking history (current typical frequency and quantity of alcohol use), history of problems related to alcohol use (Young Adult Alcohol Problems Screening Test, Hurlbut \& Sher, 1992; Short Michigan Alcohol Screening Test, Selzer, Vinokur, \& van Rooijen, 1975), and filled out a personality assessment measuring trait affectivity (Brief Multidimensional Personality Questionnaire, Patrick, Curtin, \& Tellegen, 2002). Scores for all measures were calculated according to published guidelines. Participants were then debriefed and those in the no-alcohol and placebo conditions were paid and dismissed. Participants in the alcohol condition remained at the study site until their BAC reached $0.029 \%$ or lower, at which point they were paid and dismissed.

\section{Eyeblink startle response magnitude measurement}

Electromyographic activity in the orbicularis oculi muscle was sampled at $2500 \mathrm{~Hz}$ with a bandpass filter $(1-500 \mathrm{~Hz})$ from electrodes placed under the right eye according to published guidelines (Blumenthal et al., 2005; van Boxtel, Boelhouwer, \& Bos, 1998). Eyeblink startle response magnitude was measured to startle-eliciting noise probes $(50 \mathrm{~ms}$ of $102 \mathrm{~dB}$ white noise with near instantaneous rise time). A total of 24 noise probes (6x each) were presented at 4.5 seconds post cue onset during a subset of certain and uncertain duration shock and noshock cues. Twelve noise probes ( $2 \mathrm{x}$ per time and condition) were presented at 19.5, 49.5 and 79.5 seconds post cue onset during a subset of the longer uncertain duration shock and no-shock cues. An additional 24 probes ( $6 \mathrm{x}$ per block) were presented during ITIs in the certain and uncertain duration shock and no-shock blocks to decrease probe predictability. Serial position of the probes was counterbalanced within-subjects. Offline processing of startle magnitude included epoching ( -50 to $250 \mathrm{~ms}$ surrounding noise probe), high pass filtering ( $28 \mathrm{~Hz}, 4^{\text {th }}$ order Butterworth), smoothing (signal rectification followed by $30 \mathrm{~Hz}$, $4^{\text {th }}$ order Butterworth low pass filter), and baseline correction. Startle magnitude was scored as the peak response between $20-120 \mathrm{~ms}$ post-probe onset. Trials with greater than $40 \mu \mathrm{V}$ deflections in the $50 \mathrm{~ms}$ pre-probe baseline were rejected as artifact (i.e., unstable baseline). Startle potentiation was calculated as the increase in startle magnitude during shock cues relative to the matched no-shock cues. Startle potentiation was calculated separately for $4.5 \mathrm{~s}$ probes for both certain and uncertain cues, and later times (mean across 19.5, 49.5 and 79.5 s) during uncertain cues.

\section{Results}

Data analysis and figure preparation were accomplished with $\mathrm{R}$ (R Core Team, 2012). We provide descriptive statistics for the sample, separately for Alcohol, Placebo, and NoAlcohol groups, in Table 1. General Linear Model (GLM) analyses were conducted to test all hypotheses. Raw GLM parameter estimates $(B \mathrm{~s})$ and partial eta ${ }^{2}\left(\mathrm{p} \eta^{2}\right)$ are reported to document effect sizes.

\section{Certain vs. Uncertain Duration Cues}

We analyzed startle potentiation at 4.5 s post-cue onset in a General Linear Model (GLM) with a between-subjects regressor for Beverage Group (Alcohol vs. Control) and repeated 
measures on Cue Type (Certain vs. Uncertain) ${ }^{\text {ii }}$, iii. We included two covariates, Baseline startle response and Sex, as additive regressors to increase power ${ }^{\mathrm{iv}}$. As predicted, we observed a significant interaction between Beverage Group and Cue Type, $B=22.2$, $\eta^{2}=$ $0.16, \mathrm{t}(64)=3.45, \mathrm{p}=0.001$. This indicates that the magnitude of the alcohol SRD effect on startle potentiation (i.e., the reduction in startle potentiation among alcohol vs. control participants) was approximately $22 \mu \mathrm{V}$ greater during Uncertain than Certain Duration cues (see Figure 1). The simple effect of Beverage Group was not significant in the Certain Duration cue condition, $B=-4.1, \mathrm{p} \eta^{2}=0.00, \mathrm{t}(64)=0.52, \mathrm{p}=0.602$. In contrast, there was a significant simple effect of Beverage Group in the Uncertain Duration cue condition, $B=$ $-26.3, \mathrm{p} \eta^{2}=0.12, \mathrm{t}(64)=2.93, \mathrm{p}=0.005$, with alcohol reducing startle potentiation by approximately $26 \mu \mathrm{V}$ in this condition characterized by threat uncertainty.

\section{Early vs. Later in Uncertain Duration Cues}

In supplemental analyses, we examined the stability of the Beverage Group effects on startle potentiation across the time-course of the uncertain duration cues. This analysis was designed to determine if the Beverage Group effect detected at $4.5 \mathrm{~s}$ during uncertain cues persisted to later time points. We analyzed startle potentiation in a GLM with a betweensubjects regressors for Beverage Group (Alcohol vs. Control) and repeated measures for Probe Time (Early vs. Late). We included additive regressors for Baseline startle and Sex covariates as in earlier analyses. The Beverage Group X Probe Time interaction was not significant, $B=-2.8, \mathrm{p} \eta^{2}=0.00, \mathrm{t}(64)=0.47, \mathrm{p}=0.639$ (see Figure 2). In addition, the simple effects of Beverage Group were significant for both early (reported above) and late probe times, $B=-23.5, \mathrm{p} \eta^{2}=0.09, \mathrm{t}(64)=2.59, \mathrm{p}=0.012$. These results confirm that the effect of alcohol on startle potentiation was sustained throughout the entire uncertain cue period.

\section{Individual Difference Moderator Analyses}

Supplemental analyses were conducted to determine if the Beverage Group X Cue Type effect were moderated by relevant individual differences in alcohol use (Drinks/Week), Binge Drinking Status (Yes or No; defined as typical use of $>4 / 5$ drinks for women/men in a drinking episode; Wechsler et al., 1994), self-reported alcohol problems (YAAPS past year; SMAST), and personality (Positive Emotionality, Negative Emotionality, and Constraint). Separate analyses were conducted for each individual difference measure. Each GLM included between subject regressors for Beverage Group, the individual difference measure (mean-centered) and their interaction and repeated measures on Cue Type (Certain vs. Uncertain). We included additive regressors for Baseline startle and Sex covariates as in earlier analyses. The critical test for each model was the Individual Difference X Beverage Group X Cue Type effect.

\footnotetext{
ii Preliminary analysis included two between-subjects regressors to code for the original three levels of Beverage Group (Alcohol vs. Placebo vs. No-Alcohol). We included separate No-Alcohol and Placebo groups to rule out the possibility of expectancy effects regarding alcohol SRD. No overall or interactive effects involving the Placebo vs. No-Alcohol contrast were significant. Therefore, we combined these two groups into one control group in final analyses.

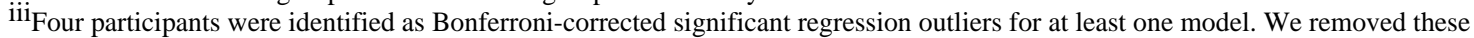
participants from all analyses. Final $\mathrm{N}=68$.

${ }^{1 \mathrm{~V}}$ We tested for Baseline startle and Sex interactions in preliminary analyses. However, no interactions involving Sex or Baseline startle were significant. Therefore, final analyses included these two covariates additively.
} 
A significant Binge Drinking Status X Beverage Group X Cue Type interaction was observed, $B=-30.3, \mathrm{p}^{2}=0.08, \mathrm{t}(61)=2.36 \mathrm{p}=.021$. Follow-up analyses indicated that the simple interaction of Beverage Group and Cue Type was significant for non-bingers, $B=$ $39.2, \mathrm{p}^{2}=0.22, \mathrm{t}(61)=4.16, \mathrm{p}<0.001$. In contrast, Beverage Group X Cue Type interaction was not significant for bingers, $B=8.9, \mathrm{p}^{2}=0.02, \mathrm{t}(61)=1.05, \mathrm{p}=0.298$ (see Figure 3).

A significant Negative Emotionality (NEM) X Beverage Group X Cue Type interaction was observed, $B=1.6, \mathrm{p}^{2}=0.13, \mathrm{t}(62)=2.99 \mathrm{p}=.004$. Follow-up analyses indicated that the simple interaction of NEM with the Beverage Group effect was not significant during Certain Duration cues, $B=0.2, \mathrm{p} \eta^{2}=0.00, \mathrm{t}(62)=0.28, \mathrm{p}=0.783$. In contrast, there was a significant simple interaction of NEM with Beverage Group during Uncertain Duration Cues, $B=-1.4, \mathrm{p} \eta^{2}=0.06, \mathrm{t}(62)=2.00, \mathrm{p}=0.049$ (see Figure 4). This indicates that the absolute magnitude of the alcohol SRD effect increased by over $1 \mu \mathrm{V}$ for every one unit increase in NEM, but only during uncertain duration cues.

No other significant individual difference $\mathrm{X}$ Beverage Group or individual difference $\mathrm{X}$ Beverage group X Cue Type effects were found for any individual difference measures.

\section{Discussion}

In this report, we described results from a novel task that manipulated threat uncertainty in the temporal domain in humans. This task was translated directly from basic affective neuroscience research designed to parse the neurobiology of anxiety vs. fear in rodents (Davis, 2006; Davis et al., 2010; Walker \& Davis, 2008; Walker, Toufexis, \& Davis, 2003), and provided the opportunity to test for predicted alcohol SRD during temporally uncertain vs. temporally certain/imminent threat of electric shock. We confirmed robust alcohol SRD when participants were presented with cues that signaled subsequent administration of electric shock, but provided little additional information about when these shocks would be administered. Alcohol SRD was observed immediately following onset of these uncertain cues, but it also persisted throughout the duration of the uncertain cues. In contrast, no significant alcohol SRD was observed during cues that signaled temporally certain, imminent shock administration. Of further interest, the magnitude of alcohol SRD during uncertain threat was moderated by individual differences in trait negative emotionality (NEM) and binge drinking status. In the following sections, we unpack these central results, identify connections to other relevant research in humans and animals, and explicate clinical implications, important limitations, and near-term future directions.

\section{Selective Alcohol SRD during Uncertain Threat}

Startle potentiation provided the primary measure of negative affective response to threat, and was used to assess alcohol SRD during certain, imminent vs. uncertain threat in this experiment. Startle potentiation measured at $4.5 \mathrm{~s}$ post-cue onset provided a particularly well-controlled test of the moderating role of temporal uncertainty on alcohol SRD, as participants' perceptual experience was identical across certain and uncertain threat cues at this measurement point (4.5 s viewing a colored square). Participants also knew that electric shock administration was $100 \%$ probable at cue-offset across both conditions per task instructions and design. However, the two conditions differed starkly at this point with 
respect to the temporal certainty regarding this upcoming aversive stimulation. In certain threat, participants knew that shock administration was imminent, whereas during uncertain threat, the cues provided very little information about the timing of shock administration. Shock administration could occur immediately or it could be up to almost three minutes into the future. This simple manipulation was sufficient to moderate the magnitude of alcohol SRD. Alcohol significantly reduced startle potentiation during temporally uncertain threat but not during imminent, certain threat. This demonstration of significant alcohol SRD during uncertain threat condition confirms that temporal uncertainty alone appears sufficient to observe SRD.

The inclusion of longer uncertain duration cues in this task allowed us to confirm that startle potentiation was sustained at later time points, and to test if alcohol SRD effects persisted through these later time points. The phenomenology of anxiety vs. fear suggests important differences in the time course of these responses. Fear appears more phasic and punctate whereas anxiety is more sustained in duration (Davis et al., 2010). Our previous manipulations of uncertain threat have not provided this important confirmation about persistent alcohol SRD during longer duration anxious responding (Hefner \& Curtin, 2012; Moberg \& Curtin, 2009). In this task, we observed sustained startle potentiation throughout the longer duration uncertain cues (measured at 19.5, 49.5, and 79.5 seconds). More importantly, alcohol SRD was evident throughout this period, indicating that temporal uncertainty elicits sustained anxious responding that is sensitive to alcohol's anxiolytic effects.

\section{Alcohol SRD and Threat Uncertainty, Broadly Defined}

These findings join other recent reports that examined threat uncertainty through quite different manipulations (i.e., non-contingent/unpredictable shock administration, Moberg \& Curtin, 2009; low probability shock administration, Hefner \& Curtin, 2012). The current findings suggest that temporal uncertainty regarding shocks is sufficient to observe alcohol SRD. However, Hefner \& Curtin (2012) demonstrated that low probability shock (20\% and, to a lesser degree, $60 \%$ cue-shock pairing) is also sufficient to observe alcohol SRD even when these shocks are administered imminently with high temporal certainty (i.e. all shocks administered on termination of 5 second cues). Synthesis of these findings suggests that alcohol SRD is robustly observed whenever threats are imprecisely signaled regardless of the source of that imprecision (i.e., uncertainty if or uncertainty when a shock will be administered).

Further evidence that the manipulations across these three experiments successfully tap a common construct, threat uncertainty, is offered by the consistency of the magnitude of the alcohol SRD effects. The two GLM coefficients (Bs) for the alcohol effects from each experiment quantify the difference in startle potentiation (measured in microvolts) in the alcohol vs. control group during certain and uncertain threat. The Bs for the alcohol effect during certain threat were $-4,-5$, and -3 , respectively, for the current experiment, Moberg \& Curtin (2009) and Hefner \& Curtin (2012). These Bs indicate that startle potentiation was modestly reduced by alcohol during certain threat but all three Bs were non-significant. In contrast, the Bs for the alcohol effect during uncertain threat were $-26,-26, \&-20$ for these 
same three experiments, respectively. Alcohol robustly reduced startle potentiation during uncertain threat and all Bs were significant. This consistency of the magnitude of the alcohol effect during uncertain threat was observed despite our use of distinct manipulations of uncertainty across these three experiments. Furthermore, uncertain threat produced descriptively higher startle potentiation than certain threat in all three experiments among our sober control participants. However, this uncertain vs. certain contrast among controls was only significant in Hefner \& Curtin (2012).

Important, outstanding questions remain regarding the necessary characteristics of the uncertain threats that are blunted by alcohol. In their basic research on the neural mechanisms of these threat effects in rodents, Davis and colleagues have used threats that most closely resemble the temporally certain and uncertain shock threats used in the current report (for review, see Davis et al., 2010), as well as other longer duration uncertain threats such as predator odor or bright light. As such, these researchers have proposed that the key characteristic that distinguishes certain and uncertain threats is threat duration. Certain threats are brief (e.g., a few seconds), whereas uncertain threats are sustained over minutes or longer. The results from this report are consistent with their thesis. However, the threat probability manipulation in Hefner \& Curtin (2012) demonstrated comparable alcohol SRD with a brief, low probability, uncertain threat cue. Additional experiments with brief uncertain threats will be necessary to resolve this issue. These experiments could manipulate uncertainty regarding shock intensity or location on the body to determine if alcohol SRD can reliably observed during brief, imminent threats that are uncertain regarding other threat characteristics. Recent research has also confirmed associations between subjective perception of the passage of time and both cognitive control and impulsivity (Wittmann, Simmons, Aron, \& Paulus, 2010; Wittmann et al., 2011). As such, future research should examine time perception as a possible mechanism for alcohol's SRD effect during longer duration threat cues.

We have offered fully unpredictable threat, temporally uncertain threat, and low probability threat as distinct manipulations of an underlying construct of threat uncertainty. However, questions remain about the relationship between threat probability and uncertainty. Hefner $\&$ Curtin (2012) observed the greatest alcohol SRD during 20\% shock threat. However, 50\% threat probability could be argued to be the most uncertain regarding likelihood of shock administration. Hefner \& Curtin (2012) did not include this condition, but did observe that alcohol SRD was greater during $60 \%$ shock threat vs. $100 \%$ shock threat. Others have proposed that both temporal and probability characteristics associated with threat track monotonically along a predatory threat imminence continuum (Bolles \& Fanselow, 1988; Fanselow \& Lester, 1988; Mobbs et al., 2009). If true, all three of our recent experiments may have contrasted the two ends of this imminence continuum. Future research that parametrically manipulates threat probability across conditions that include $100 \%, 50 \%$ and threat probabilities equi-distant from $50 \%$ (e.g., $20 \%$ \& $70 \%$ ) could further inform these competing perspectives on probability, imminence, and uncertainty. In addition, future research should measure subjective uncertainty during threat anticipation, as objective and subjective uncertainty may not be linearly related. 


\section{Cognitive and Neural Mechanisms of Threat Uncertainty}

Available evidence in humans and animal models suggests that certain and uncertain threats elicit distinct patterns of attention that are functionally adaptive given the unique demands of these two classes of threat (Baas, Milstein, Donlevy, \& Grillon, 2006; Blanchard, Griebel, Pobbe, \& Blanchard, 2011; Cornwell et al., 2007, 2008; Grillon \& Baas, 2003). When threats are well-defined, highly probable, and imminent, attention is selectively directed toward the source of the threat, while processing of peripheral, non-threat stimuli is degraded. This selective, threat-focused pattern of attention may facilitate preparation of fight, flight or other immediate adaptive behavioral response to the impending threat. When threats are ambiguous, distal or otherwise less certain, attention is distributed broadly across sensory modalities and stimuli in the environment. This vigilance and information gathering state increases the probability of threat detection if threats subsequently approach in space and/or time or risk otherwise increases. However, this vigilance state may impose a substantial cognitive load on the organism (Shackman et al., 2006; Shackman et al., 2011).

Influential theories have proposed that alcohol's SRD effects are mediated via impairment in attention and threat appraisal when intoxicated, such that intoxicated individuals display reduced response to threats that are presented in the periphery of salient distracters (Steele \& Josephs, 1990; see Curtin et al., 1998, 2001 for empirical support using startle potentiation). Similarly,Sayette (1993) suggested that alcohol SRD occurs in contexts where threats would not be adequately appraised due to the nature and timing of these threats relative to when the individual started drinking. It may be that salient distracters and other manipulations that degrade threat cue appraisal generally increase uncertainty regarding the nature of the threat. These threats should recruit the neural circuits involved in processing uncertain threats, which appear to be more sensitive to alcohol. In contrast, when clear threats are presented in the focus of attention, the onset and nature of the threat may be substantially more certain and thus the effect of alcohol may be diminished.

Davis, Walker, and colleagues have demonstrated startle potentiation during temporally uncertain threat in rodents is mediated by NE and CRF sensitive pathways through the lateral divisions of the CeA and BNST (Campeau \& Davis, 1995; Davis et al., 2010; Hitchcock \& Davis, 1987; Miles et al., 2011; Walker \& Davis, 1997a, 1997b, 2008). Although our tasks are careful, animal-to-human translations, speculation regarding the contribution of these same mechanisms to alcohol SRD in humans must be advanced cautiously. Our participants are instructed about the threat contingencies, whereas the contingencies are established via implicit learning in rodents. Our use of threat contingency instruction follows from our focus on the expression rather than acquisition of emotional responses to threats. Furthermore, human neuroimaging evidence suggests similar neural structures are involved in the response to threats established by instruction (Alvarez et al., 2011; Delgado et al., 2006; Phelps et al., 2001). Nonetheless, these mechanisms need to be directly assessed.

Preliminary evidence is now emerging regarding the neural mechanisms of uncertain threat in humans. Consistent with animal models, confirmed that certain and uncertain threats elicit distinct patterns of brain activity using fMRI in a virtual reality version of the Grillon's NPU task. Both classes of threats produced activity in the dorsal amygdala. However, only 
uncertain threats recruited sustained activity in the BNST. In addition, uncertain threats evoked activity in the hippocampus, and cortical regions including the anterior insula, anterior cingulate, and a frontoparietal cortical network associated with hypervigilance. In an elegant series of studies, Mobbs and colleagues observed increased activity in forebrain structures including the vmPFC, hippocampus, hypothalamus, and amygdala when threats were distal and less certain (Mobbs et al., 2007, 2009). In contrast, imminent threats were associated with activity in midbrain regions including the periaqueductal gray and cortical regions that are involved in analgesia and panic. These findings dovetail nicely with our earlier descriptions of the distinct patterns of attention and vigilance required to respond adaptively to the unique demands of these two classes of threat. These results also clearly implicate top-down, cortical mechanisms that could also mediate alcohol SRD during uncertain threat.

The role of NE and CRF mechanisms in the extended amygdala in response to uncertain threat and alcohol SRD during uncertain threat can be evaluated via direct pharmacological manipulations of these neurotransmitter systems in humans. Of interest, a number of laboratories are also currently exploring the possibility of repurposing CRF and NE antagonists for the treatment of stress-induced relapse in addiction (Koob \& Zorrilla, 2012). As such, this research may address both etiological mechanisms and treatment simultaneously.

\section{Individual Difference Risk Factors}

The magnitude of alcohol SRD during uncertain threat was reduced among individuals who self-reported typical binge alcohol use in their recent drinking outside the laboratory. Additional developmental and/or longitudinal research is necessary to determine if this individual difference moderator reflects a pre-morbid etiological risk factor for alcoholism within a model such as Schuckit's Low Response to Alcohol theory (Schuckit et al., 2009; Schuckit \& Smith, 2006). If true, participants' pattern of binge alcohol use may reflect attempts to increase the otherwise modest SRD they received with more healthy, regulated alcohol use by consuming larger doses of alcohol in each drinking episode. Alternatively, this reduced alcohol SRD among binge drinkers may reflect the development of alcohol tolerance following heavy use rather than a risk factor that preceded alcohol exposure. However, the development of tolerance to alcohol SRD could also motivate these drinkers to pursue increasingly heavier, hazardous levels of use to obtain these rewarding effects.

Trait negative emotionality (NEM) as assessed by the Multidimensional Personality Questionnaire significantly moderated the magnitude of the alcohol SRD effect selectively to uncertain duration cues. Those reporting higher levels of NEM displayed the greatest alcohol SRD effect on startle potentiation to uncertain duration shock cues. Higher scores on NEM mark the disposition to experience negative emotions and are linked conceptually to the brain motivation system underlying defensive-withdrawal behaviors (Lang, 1995; Sutton \& Davidson, 1997; Watson et al., 1999). Furthermore, individual differences in NEM are correlated with negative affective response and physiological reactions to motivationally relevant threat stimuli (Cacioppo \& Berntson, 1994; Lang, 1995; Witvliet \& Vrana, 1995). The observed moderation of alcohol SRD by NEM in this experiment suggests that 
individuals characterized by high trait negative emotionality may receive increased negative reinforcement via reduction of anxiety from their alcohol use. This association between individual differences in NEM and the magnitude of alcohol SRD could result in a greater propensity to "self-medicate" negative emotions. It also may contribute to increased frequency of alcohol use among individuals who drink to cope with stress (Cooper et al., 1995; Schroder \& Perrine, 2007).

Hefner \& Curtin (2012) observed a similar moderating role for NEM regarding alcohol SRD during uncertain threat using a distinct manipulation of threat uncertainty (i.e., low vs. high probability threat). This increases our confidence that this individual difference moderating effect is broadly replicable. Affective neuroscience research has established threat biased cognitive-attentional function among individuals with higher trait anxiety that may reflect atypical processing in pre-frontal-amygdala circuitry (Bishop, Duncan, Brett, \& Lawrence, 2004; Dvorak-Bertsch, Curtin, Rubinstein, \& Newman, 2007). Furthermore, these biases are also reflected in greater reactivity to ambiguous stimuli that may share many properties with our uncertain threats (Bishop, 2007; Li, Zinbarg, \& Paller, 2007). If alcohol undermines cognitive-attentional functions relevant for uncertain threat processing, these trait anxious individuals may have more to gain from their alcohol use. Of course, these speculations must be advanced very cautiously at this point for numerous reasons. Foremost among these caveats is that NEM indexes broad individual differences in defensive reactivity rather than anxiety specifically. Future work needs to more precisely index individual differences in anxiety and also related constructs such as intolerance of uncertainty (Gosselin, 2008). As noted earlier, future research also needs to more directly measure the cognitive attentional processes that may mediate these individual difference effects.

\section{Implications for Psychiatric Disorders and Intoxicated Behaviors}

The selective effect of alcohol on uncertain threats in this and our other recent experiments may contribute to the patterns of co-morbidity between alcohol use disorders and various anxiety disorders. Generalized anxiety disorder (GAD) and post-traumatic stress disorder (PTSD) are highly co-morbid with alcohol use disorders (Grant et al., 2005; Kessler et al., 1995). In contrast, the prevalence of alcohol use disorders is not elevated among individuals with simple phobias (Kushner et al., 1990). Both GAD and PTSD appear to involve sustained negative affective in complex multimodal contexts without simple, distinct cues to identify the explicit nature and timing of the potential threat. In fact, manipulations involving unpredictable threat have been used to study etiologic processes for these disorders (Grillon, 2002). Alcohol may be particularly effective at reducing negative affect for patients with these disorders involving exaggerated response to uncertain threats. As such, their alcohol use would be strongly reinforced and increased frequency and quantity of use would not be surprising. Conversely, if alcohol has less effect on more certain threats, patients with simple phobias, for example, would receive relatively less reinforcement for excessive use of alcohol.

Neuroadaptation of the stress response has been implicated as a critical mechanism in addiction etiology across addictive drugs including alcohol, benzodiazepines, opiates, cocaine, nicotine, and marijuana (Breese, Sinha, \& Heilig, 2011; Koob \& LeMoal, 2008; 
Shaham \& Hope, 2005; Sinha, 2008; Weiss, 2001). These theories proposed that repeated homeostatic adjustments in the brain's stress systems in response to chronic alcohol or drug use culminate in persistent compensatory adaptations in the structures involved in the response to stressors. Research involving the administration of acute alcohol doses can identify processes under homeostatic pressure following alcohol use. These are the processes that would be expected to exhibit compensatory neuroadaptation following chronic allostatic load produced by repeated alcohol use. If true, increased startle potentiation during uncertain threat may mark an etiologically relevant, compensatory stress neuroadaptation among alcoholics. Furthermore, this uncertain threat-induced increase in startle potentiation should be most apparent during periods of alcohol abstinence. In fact, we have confirmed this prediction in a recent experiment that demonstrated selectively greater startle potentiation during uncertain threat in recently abstinence alcoholics with the same task used in this report (Moberg \& Curtin, 2012). We also have noted similar increased startle potentiation selectively during uncertain threat among 24 hour nicotine deprived smokers (Hogle et al., 2010) and 72-hour deprived marijuana users (Gloria, Jaber, Baker, \& Curtin, 2009). These findings cautiously increase confidence that stress neuroadaptation to uncertain threats represents a shared, cross-drug, etiologic pathway in alcohol and drug dependence. In fact, Koob, (2010) has proposed that neuroadaptation in extrahypothalamic CRF systems in the extended amygdala contributes to what he has labeled the "dark side of addiction" across drugs of abuse.

These results regarding alcohol SRD during uncertain threat also have potential to shed light on factors that contribute to some hazardous behaviors observed among intoxicated drinkers. For example, alcohol-impaired driving continues to be a serious public health concern, particularly in situations involving fatal car accidents (Brady \& Li, 2013). If intoxicated drinkers respond less robustly to uncertain threats, it is not surprising that policies that focus on legal consequences following conviction may not be particularly effective deterrents if intoxicated drinkers believe the likelihood of arrest and conviction to be low. Instead, we should focus on policies that increase drinkers' perception that risk of arrest is more certain such as highly publicized sobriety check points, given that responding to certain threats appears relatively spared when intoxicated (Ferguson, 2012).

\section{Limitations and Future Directions}

Startle potentiation remains an attractive measure of negative affect because it can be used cross-species to facilitate animal-human translational research. As such, we have detailed knowledge of the neurobiology of the startle response and its potentiation (Davis, 1989, 2006; Grillon et al., 2007). Startle potentiation also can be measured with both minimal disruption of task-related processes and reduced influence by demand characteristics than measures under volitional control (e.g., self-report). Despite these advantages associated with startle potentiation measurement, future tests of alcohol SRD during threat uncertainty should use more diverse dependent measures of negative affective response including other physiology, self-report, and behavioral measures. Cross-validation of selective alcohol SRD during threat uncertainty across distinct negative affect response systems will reduce concerns about alternative explanations that are dependent measure specific and may provide further insight into the mechanism(s) of this effect. Furthermore, measures of 
attention (e.g., ERPs, pre-pulse inhibition of startle) should be examined given likely differences in attention function during anxiety vs. fear (Cornwell et al., 2008; Mobbs et al., 2007, 2009). Tests of alcohol SRD should also be conducted in tasks that elicit anxiety with aversive stimuli other than shock. For example, tasks that elicit anxiety during exposure to darkness (Grillon et al., 2007) and $\mathrm{CO}_{2}$ challenge (Zvolensky et al., 1999) have been previously validated. These tasks are similar to manipulations that involve longer time course aversive stimuli in rodents (e.g., exposure to light, Walker \& Davis, 1997; predator odor, Fendt, Endres, \& Apfelbach, 2003; Fendt, Siegl, \& Steiniger-Brach, 2005).

Inclusion criteria in all of our alcohol SRD research required that participants self-report no other recent drug use. However, we have not biologically confirmed their self-report with drug testing other than for alcohol (via breath test). Clearly, other recent drug use could affect responding to our certain and uncertain threats. However, to the degree that participants misrepresent their recent drug use, these participants would be expected to be distributed randomly across alcohol and control groups. Thus, the impact of potential other drug use on interpretation of the observed alcohol SRD effects is expected to be negligible. Nonetheless, future research should consider the use of objective, biological tests of other recent drug use. Future research should also directly examine if alcohol SRD varies by alcohol dose. Our published research in this area has been limited to a single moderate dose (target $\mathrm{BAC}=.08 \%)$.

\section{Summary}

Anxiety and fear can be dissociated phenomenologically and neurobiologically with manipulations of threat uncertainty (Davis et al., 2010). In this report, we manipulated temporal uncertainty by contrasting alcohol SRD during temporally uncertain shock threat vs. certain imminent threat. We demonstrated selective alcohol SRD during temporally uncertain threats, and provided much-needed evidence that this alcohol SRD is sustained over time. These results were obtained in a task that was translated with a high degree of fidelity from basic affective neuroscience with rodents (Davis et al., 2010; Walker \& Davis, 2008; Walker et al., 2003). We also demonstrated that individual differences in trait negative emotionality and binge drinking status moderated alcohol SRD during uncertain threat.

These individual differences are offered as possible markers for individual differences in the strength of alcohol SRD. They may also mark the potential to develop stress neuroadaptation following chronic alcohol use. These results provide a solid foundation on which to explore such stress neuroadaptations following chronic alcohol (or other drug) use. The selectivity of alcohol SRD during uncertain threat implicates an etiologic pathway that may contribute to comorbidity between alcohol dependence and some anxiety disorders. Finally, our novel manipulations of threat uncertain in this and other recent reports (Hefner \& Curtin, 2012; Moberg \& Curtin, 2009) may prove valuable to clinical scientists examining the contribution of anxiety to various forms of psychopathology.

\section{Acknowledgments}

Funding was provided by a grant to J. Curtin from NIAAA (R01 AA15384). 


\section{References}

Alvarez RP, Chen G, Bodurka J, Kaplan R, Grillon C. Phasic and sustained fear in humans elicits distinct patterns of brain activity. NeuroImage. 2011; 55(1):389-400. [PubMed: 21111828]

Baas JMP, Milstein J, Donlevy M, Grillon C. Brainstem correlates of defensive states in humans. Biological psychiatry. 2006; 59(7):588-593. [PubMed: 16388780]

Bishop S. Neurocognitive mechanisms of anxiety: an integrative account. Trends in Cognitive Sciences. 2007; 11(7):307-316. [PubMed: 17553730]

Bishop S, Duncan J, Brett M, Lawrence AD. Prefrontal cortical function and anxiety: controlling attention to threat-related stimuli. Nature neuroscience. 2004; 7(2):184-8.

Blanchard DC, Griebel G, Pobbe R, Blanchard RJ. Risk assessment as an evolved threat detection and analysis process. Neuroscience \& Biobehavioral Reviews. 2011; 35(4):991-998. [PubMed: 21056591]

Blanchard DC, Blanchard RJ. Defensive behaviors, fear, and anxiety. Handbook of Anxiety and Fear (1st ed). 2008; Vol. 17

Blumenthal TD, Cuthbert BN, Filion DL, Hackley S, Lipp OV, van Boxtel A. Committee report: Guidelines for human startle eyeblink electromyographic studies. Psychophysiology. 2005; 42(1):115. [PubMed: 15720576]

Bolles RC, Fanselow MS. A perceptual-defensive-recuperative model of fear and pain. Behavioral and Brain Sciences. 1988; 3:291-301.

Brady JE, Li G. Prevalence of alcohol and other drugs in fatally injured drivers. Addiction (Abingdon, England). 2013; 108(1):104-114.

Breese GR, Sinha R, Heilig M. Chronic alcohol neuroadaptation and stress contribute to susceptibility for alcohol craving and relapse. Pharmacology \& Therapeutics. 2011; 129(2):149-171. [PubMed: 20951730]

Brown SA, Vik PW, Patterson TL, Grant I, Schuckit MA. Stress, vulnerability and adult alcohol relapse. Journal of Studies on Alcohol. 1995; 56:538-545. [PubMed: 7475034]

Cacioppo JT, Berntson GG. Relationship between attitudes and evaluative space: A critical review, with emphasis on the separability of positive and negative substrates. Psychological Bulletin. 1994; 115(3):401-423.

Campeau S, Davis M. Involvement of subcortical and cortical afferents to the lateral nucleus of the amygdala in fear conditioning measured with fear-potentiated startle in rats trained concurrently with auditory and visual conditioned stimuli. Journal of Neuroscience. 1995; 15(3, Pt 2):23122327. [PubMed: 7891169]

Cooper ML, Frone MR, Russell M, Mudar P. Drinking to regulate positive and negative emotions: A motivational model of alcohol use. Journal of Personality \& Social Psychology. 1995; 69(5):990_ 1005. [PubMed: 7473043]

Cornwell BR, Baas JMP, Johnson L, Holroyd T, Carver FW, Lissek S, Grillon C. Neural responses to auditory stimulus deviance under threat of electric shock revealed by spatially-filtered magnetoencephalography. NeuroImage. 2007; 37(1):282-289. [PubMed: 17566766]

Cornwell BR, Echiverri AM, Covington MF, Grillon C. Modality-specific attention under imminent but not remote threat of shock: Evidence from differential prepulse inhibition of startle. Psychological Science. 2008; 19(6):615-622. [PubMed: 18578853]

Curtin JJ, Fairchild BA. Alcohol and cognitive control: Implications for regulation of behavior during response conflict. Journal of Abnormal Psychology. 2003; 112(3):424-436. [PubMed: 12943021]

Curtin JJ, Lang AR, Patrick CJ, Stritzke WGK. Alcohol and fear-potentiated startle: The role of competing cognitive demands in the stress-reducing effects of intoxication. Journal of Abnormal Psychology. 1998; 107(4):547-565. [PubMed: 9830242]

Curtin JJ, Patrick CJ, Lang AR, Cacioppo JT, Birbaumer N. Alcohol affects emotion through cognition. Psychological Science. 2001; 12(6):527-531. [PubMed: 11760143]

Davis M. Neural systems involved in fear-potentiated startle. Annals of the New York Academy of Sciences. 1989; 563:165-183. [PubMed: 2570545] 
Davis M. Neural systems involved in fear and anxiety measured with fear-potentiated startle. American Psychologist. 2006:741-756. [PubMed: 17115806]

Davis M, Antoniadis E, Amaral D, Winslow J. Acoustic startle reflex in rhesus monkeys: A review. Reviews in the Neurosciences. 2008; 19:171-185. [PubMed: 18751523]

Davis M, Walker DL, Miles L, Grillon C. Phasic vs Sustained Fear in Rats and Humans: Role of the Extended Amygdala in Fear vs Anxiety. Neuropsychopharmacology Reviews. 2010; 35:105-135. [PubMed: 19693004]

Delgado MR, Olsson A, Phelps EA. Extending animal models of fear conditioning to humans. Biological Psychology. 2006; 73:39-48. [PubMed: 16472906]

Dvorak-Bertsch JD, Curtin JJ, Rubinstein TJ, Newman JP. Anxiety moderates the interplay between cognitive and affective processing. Psychological Science. 2007; 18:699-705. [PubMed: 17680941]

Fanselow, MS.; Lester, LS. A functional behavioristic approach to aversively motivated behavior: predatory imminence as a determinant of the topography of defensive behavior. In: Bolles, RC.; Beecher, MD., editors. Evolution and Learning. Hillsdale, NJ: Erlbaum; 1988. p. 185-212.

Fendt M, Endres T, Apfelbach R. Temporary inactivation of the bed nucleus of the stria terminalis but not of the amygdala blocks freezing induced by trimethylthiazoline, a component of fox feces. The Journal of Neuroscience. 2003; 23(1):23-28. [PubMed: 12514197]

Fendt M, Siegl S, Steiniger-Brach B. Noradrenaline transmission within the ventral bed nucleus of the stria terminalis is critical for fear behavior induced by trimethylthiazoline, a component of fox odor. The Journal of Neuroscience. 2005; 25(25):5998-6004. [PubMed: 15976089]

Ferguson SA. Alcohol-impaired driving in the United States: contributors to the problem and effective countermeasures. Traffic injury prevention. 2012; 13(5):427-441. [PubMed: 22931172]

Gloria R, Jaber JN, Baker TB, Curtin JJ. The effect of temporal precision and probability on the response to threat of shock: a fear-potentiated startle study. Psychophysiology. 2009; 46(s1):s80.

Gosselin P. Evaluation of intolerance of uncertainty: Development and validation of a new self-report measure. Journal of Anxiety Disorders. 2008; (22):1427-1439. [PubMed: 18395409]

Grant BF, Stinson FS, Dawson DA, Chou SP, Dufour MC, Compton W, Pickering RP, et al. Prevalence and Co-Occurrence of Substance Use Disorders and Independent Mood and Anxiety Disorders: Results From the National Epidemiologic Survey on Alcohol and Related Conditions. Arch Gen Psychiatry. 2006; 29(2)

Grillon C. Models and mechanisms of anxiety: evidence from startle studies. Psychopharmacology. 2008; 199(3):421-437. [PubMed: 18058089]

Grillon C, Baas JM. A review of the modulation of the startle reflex by affective states and its application in psychiatry. Clinical Neurophysiology. 2003; 144(9):1557-1579. [PubMed: 12948786]

Grillon C, Baas JP, Lissek S, Smith K, Milstein J. Anxious Responses to Predictable and Unpredictable Aversive Events. Behavioral Neuroscience. 2004; 118(5):916-924. [PubMed: 15506874]

Grillon C, Duncko R, Covington MF, Kopperman L, Kling MA. Acute stress potentiates anxiety in humans. Biological Psychiatry. 2007; 62:1183-1186. [PubMed: 17692829]

Grillon C, Pellowski M, Merikangas KR, Davis M. Darkness facilitates the acoustic startle reflex in humans. Biological Psychiatry. 1997; 42(6):453-460. [PubMed: 9285081]

Hefner KR, Curtin JJ. Alcohol stress response dampening: selective reduction of anxiety in the face of uncertain threat. Journal of Psychopharmacology (Oxford, England). 2012; 26(2):232-244.

Hitchcock JM, Davis M. Fear-potentiated startle using an auditory conditioned stimulus: effect of lesions of the amygdala. Physiology \& behavior. 1987; 39(3):403-408. [PubMed: 3575483]

Hogle JM, Curtin JJ. Sex differences in negative affective response during nicotine withdrawal. Psychophysiology. 2006; 43(4):344-356. [PubMed: 16916430]

Hogle JM, Kaye JT, Curtin JJ. Nicotine withdrawal increases threat-induced anxiety but not fear: neuroadaptation in human addiction. Biological Psychiatry. 2010; 68:719-725. [PubMed: 20673878]

Hurlbut SC, Sher KJ. Assessing alcohol problems in college students. Journal of American College Health. 1992; 41(2):49-58. [PubMed: 1460173] 
Kessler RC. Posttraumatic stress disorder in the national comorbidity survey. Arch Gen Psychiatry. 1995; 52:1048-1060. [PubMed: 7492257]

Koob GF. The role of CRF and CRF-related peptides in the dark side of addiction. Brain Research. 2010; 1314:3-14. [PubMed: 19912996]

Koob GF, LeMoal ML. Addiction and the Brain Antireward System. Annual Review of Psychology. 2008; 59:29-53.

Koob GF, Volkow ND. Neurocircuitry of Addiction. Neuropsychopharmacology Reviews. 2010; 35:217-238. [PubMed: 19710631]

Koob GF, Zorrilla EP. Update on Corticotropin-Releasing Factor Pharmacotherapy for Psychiatric Disorders: A Revisionist View. Neuropsychopharmacology. 2012; 37(1):308-309. [PubMed: 22157874]

Lang PJ. The emotion probe. Studies of motivation and attention. American Psychologist. 1995; 50(5): 372-85. [PubMed: 7762889]

Lê AD, Quan B, Juzytch W, Fletcher PJ, Joharchi N, Shaham Y. Reinstatement of alcohol-seeking by priming injections of alcohol and exposure to stress in rats. Psychopharmacology. 1998; 135:169174. [PubMed: 9497022]

LeDoux J. Fear and the brain: Where have we been, and where are we going? Biological Psychiatry. 1998; 44(12):1229-1238. [PubMed: 9861466]

Li W, Zinbarg RE, Paller KA. Trait anxiety modulates supraliminal and subliminal threat: Brain potential evidence for early and late processing influences. Cognitive, Affective, \& Behavioral Neuroscience. 2007; 7(1):25-36.

Liang KC, Melia KR, Miserendino MJD, Falls WA, Campeau S, Davis M. Corticotropin-releasing Factor: Long-lasting Facilitation of the Acoustic Startle Reflex. The Journal of Neuroscience. 1992; 12(6):2303-2312. [PubMed: 1351540]

McEwen BS. From molecules to mind. Stress, individual differences, and the social environment. Ann N Y Acad Sci. 2001; 935:42-9. [PubMed: 11411174]

McEwen BS, Eiland L, Hunter RG, Miller MM. Stress and anxiety: structural plasticity and epigenetic regulation as a consequence of stress. Neuropharmacology. 2012; 62(1):3-12. [PubMed: 21807003]

Miles L, Davis M, Walker D. Phasic and Sustained Fear are Pharmacologically Dissociable in Rats. Neuropsychopharmacology. 2011; 36(8):1563-1574. [PubMed: 21471958]

Mobbs D, Marchant JL, Hassabis D, Seymour B, Tan G, Gray M, Petrovic P, et al. From Threat to Fear: The Neural Organization of Defensive Fear Systems in Humans. The Journal of Neuroscience. 2009; 29:12236-12243. [PubMed: 19793982]

Mobbs D, Petrovic P, Marchant JL, Hassabis D, Weiskopf N, Seymour B, Dolan RJ, et al. When Fear Is Near: Threat Imminence Elicits Prefrontal-Periaqueductal Gray Shifts in Humans. Science. 2007; 317(5841):1079-1083. [PubMed: 17717184]

Moberg CA, Curtin JJ. Alcohol selectively reduces anxiety but not fear: startle response during unpredictable versus predictable threat. Journal of Abnormal Psychology. 2009; 118(2):335-347. [PubMed: 19413408]

Moberg CA, Curtin JJ. Stressing the importance of anxiety in alcoholism. Alcoholism: Clinical and Experimental Research. 2012; Vol. 36:60A.

Overstreet DH, Knapp DJ, Breese GR. Drug challenges reveal differences in mediation of stress facilitation of voluntary alcohol drinking and withdrawal-induced anxiety in alcohol-preferring $\mathrm{P}$ rats. Alcoholism, Clinical and Experimental Research. 2007; 31(9):1473-1481.

Patrick CJ, Curtin JJ, Tellegen A. Development and validation of a brief form of the Multidimensional Personality Questionnaire. Psychological Assessment. 2002; 14(2):150-163. [PubMed: 12056077]

Phelps EA. Emotion and cognition: Insights from studies of the human amygdala. Annual Review of Psychology. 2006; 57:27-53.

Phelps EA, LeDoux JE. Contributions of the Amygdala to Emotion Processing: From Animal Models to Human Behavior. Neuron. 2005; 48:175-187. [PubMed: 16242399]

Phelps EA, O’Connor KJ, Gatenby JC, Gore JC, Grillon C, Davis M. Activation of the left amygdala to a cognitive representation of fear. Nature neuroscience. $2001 ; 4(4): 437-41$. 
R Development Core Team. R: A language and environment for statistical computing. R Foundation for Statistical Computing. Vienna, Austria; 2008. URL http://www.R-project.org

Sapolsky, RM. Endocrinology of the stress-response. In: Becker, JB.; Breedlove, SM.; Crews, D.; McCarthy, MM., editors. Behavioral endocrinology. 2nd ed.. MIT Press; 2002. p. 409-450.

Sapolsky RM. Stress and plasticity in the limbic system. Neurochemical Research. 2003; 28(11):17351742. [PubMed: 14584827]

Sarinopoulos I, Grupe DW, Mackiewicz KL, Herrington JD, Lor M, Steege EE, Nitschke JB. Uncertainty during anticipation modulates neural responses to aversion in human insula and amygdala. Cerebral Cortex (New York NY: 1991). 2010; 20(4):929-940.

Sayette MA. An appraisal-disruption model of alcohol's effects on stress responses in social drinkers. Psychological Bulletin. 1993; 114(3):459-476. [PubMed: 8272466]

Schroder KEE, Perrine MW. Covariations of emotional states and alcohol consumption: Evidence from 2 years of daily data collection. Social Science \& Medicine. 2007; 5:2588-2602. [PubMed: 17761376]

Schuckit MA, Smith TL. An evaluation of the level of response to alcohol, externalizing symptoms, and depressive symptoms as predictors of alcoholism. Journal of Studies on Alcohol. 2006; 67:215-227. [PubMed: 16562403]

Schuckit MA, Smith TL, Danko GP, Trim R, Bucholz KK, Edenberg HJ, Hesselbrock VM, et al. An evaluation of the full level of response to alcohol model of heavy drinking and problems in COGA offspring. Journal of Studies on Alcohol and Drugs. 2009; 70(436-445):436-445. [PubMed: 19371495]

Selzer ML, Vinokur A, van Rooijen L. A self-administered Short Michigan Alcoholism Screening Test (SMAST). Journal of Studies on Alcohol. 1975; 36(1):117-126. [PubMed: 238068]

Shackman AJ, Maxwell JS, McMenamin BW, Greischar LL, Davidson RJ. Stress Potentiates Early and Attenuates Late Stages of Visual Processing. The Journal of Neuroscience. 2011; 31(3):11561161. [PubMed: 21248140]

Shackman AJ, Sarinopoulos I, Maxwell JS, Pizzagalli DA, Lavric A, Davidson RJ. Anxiety selectively disrupts visuospatial working memory. Emotion (Washington DC). 2006; 6(1):40-61.

Shaham Y, Hope BT. The role of neuroadaptations in relapse to drug seeking. Nature Neuroscience. 2005; 8(11):1437-1439.

Sher, KJ. Stress response dampening. In: Blane, HT.; Leonard, KE., editors. Psychological Theories of Drinking and Alcoholism. New York: Guilford Press; 1987. p. 227-271.

Sinha R. How does stress increase risk of drug abuse and relapse? Psychopharmacology. 2001; 158:343-359. [PubMed: 11797055]

Sinha R. Chronic stress, drug use, vulnerability to addiction. Annals of the New York Academy of Sciences. 2008; 1141:105-130. [PubMed: 18991954]

Sinha R, Fox HC, Hong KA, Hansen J, Tuit K, Kreek MJ. Effects of Adrenal Sensitivity, Stress- and Cue-Induced Craving, and Anxiety on Subsequent Alcohol Relapse and Treatment Outcomes. Arch Gen Psychiatry, archgenpsychiatry. 2011; 2011; 49

Steele CM, Josephs RA. Alcohol myopia. Its prized and dangerous effects. American psychologist. 1990; 45(8):921-33. [PubMed: 2221564]

Sutton SK, Davidson RJ. Prefrontal brain asymmetry: A biological substrate of the behavioral approach and inhibition systems. Psychological Science. 1997; 8(3):204-210.

Swerdlow NR, Geyer MA, Vale WW, Koob GF. Corticotropin-releasing factor potentiates acoustic startle in rats: Blockade by chlordiazepoxide. Psychopharmacology. 1986; 88:142-152.

van Boxtel A, Boelhouwer AJW, Bos AR. Optimal EMG signal bandwidth and interelectrode distance for the recording of acoustic, electrocutaneous and photic blink reflexes. Psychophysiology. 1998; 35(6):690-697. [PubMed: 9844430]

Volkow N, Li T-K. The neuroscience of addiction. Nature Neuroscience. 2005; 8(11):1429-1430.

Walker DL, Davis M. Anxiogenic Effects of High Illumination Levels Assessed with the Acoustic Startle Response in Rats. Society of Biological Psychiatry. 1997a; 42:461-471.

Walker DL, Davis M. Double dissociation between the involvement of the bed nucleus of the stria terminalis and the central nucleus of the amygdala in startle increases produced by conditioned 
versus unconditioned fear. The Journal of neuroscience: the official journal of the Society for Neuroscience. 1997b; 17(23):9375-9383. [PubMed: 9364083]

Walker DL, Davis M. Role of the extended amygdala in short-duration versus sustained fear: a tribute to Dr. Lennart Heimer. Brain Structure and Function. 2008; 213(1-2):29-42. [PubMed: 18528706]

Walker DL, Miles LA, Davis M. Selective participation of the bed nucleus of the stria terminalis and CRF in sustained anxiety-like versus phasic fear-like responses. Progress in Neuro-

Psychopharmacology \& Biological Psychiatry. 2009; 33(8):1291-1308. [PubMed: 19595731]

Walker DL, Toufexis DJ, Davis M. Role of the bed nucleus of the stria terminalis versus the amygdala in fear, stress, and anxiety. European Journal of Pharmacology. 2003; 463:199-216. [PubMed: 12600711]

Watson D, Wiese D, Vaidya J, Tellegen A. The two general activation systems of affect: Structural findings, evolutionary considerations, and psychobiological evidence. Journal of Personality and Social Psychology. 1999; 76(5):820-838.

Wechsler H, Davenport A, Dowdell G, Moeykens B, Castillo S. Health and behavioral consequences of binge drinking in college: A national survey of students at 140 campuses. JAMA. 1994; 272(21):1672-1677. [PubMed: 7966895]

Weiss F. Compulsive drug-seeking behavior and relapse: neuroadaptation, stress, and conditioning factors. Annals New York Academy of Sciences. 2001:1-26.

Wittmann M, Simmons AN, Aron JL, Paulus MP. Accumulation of neural activity in the posterior insula encodes the passage of time. Neuropsychologia. 2010; 48(10):3110-3120. [PubMed: 20600186]

Wittmann M, Simmons AN, Flagan T, Lane SD, Wackermann J, Paulus MP. Neural substrates of time perception and impulsivity. Brain research. 2011; 1406:43-58. [PubMed: 21763642]

Witvliet CO, Vrana SR. Psychophysiological responses as indices of affective dimensions. Psychophysiology. 1995; 32(5):436-443. [PubMed: 7568637]

Zorrilla EP, Koob GF. Progress in corticotropin-releasing factor-1 antagonist development. Drug Discovery Today. 2010; 15(9-10):371-383. [PubMed: 20206287]

Zvolensky MJ, Eifert GH, Lejuez CW, McNeil DW. The effects of offset control over 20\% carbondioxide-enriched air on anxious responding. Journal of Abnormal Psychology. 1999; 108(4):624632. [PubMed: 10609427] 

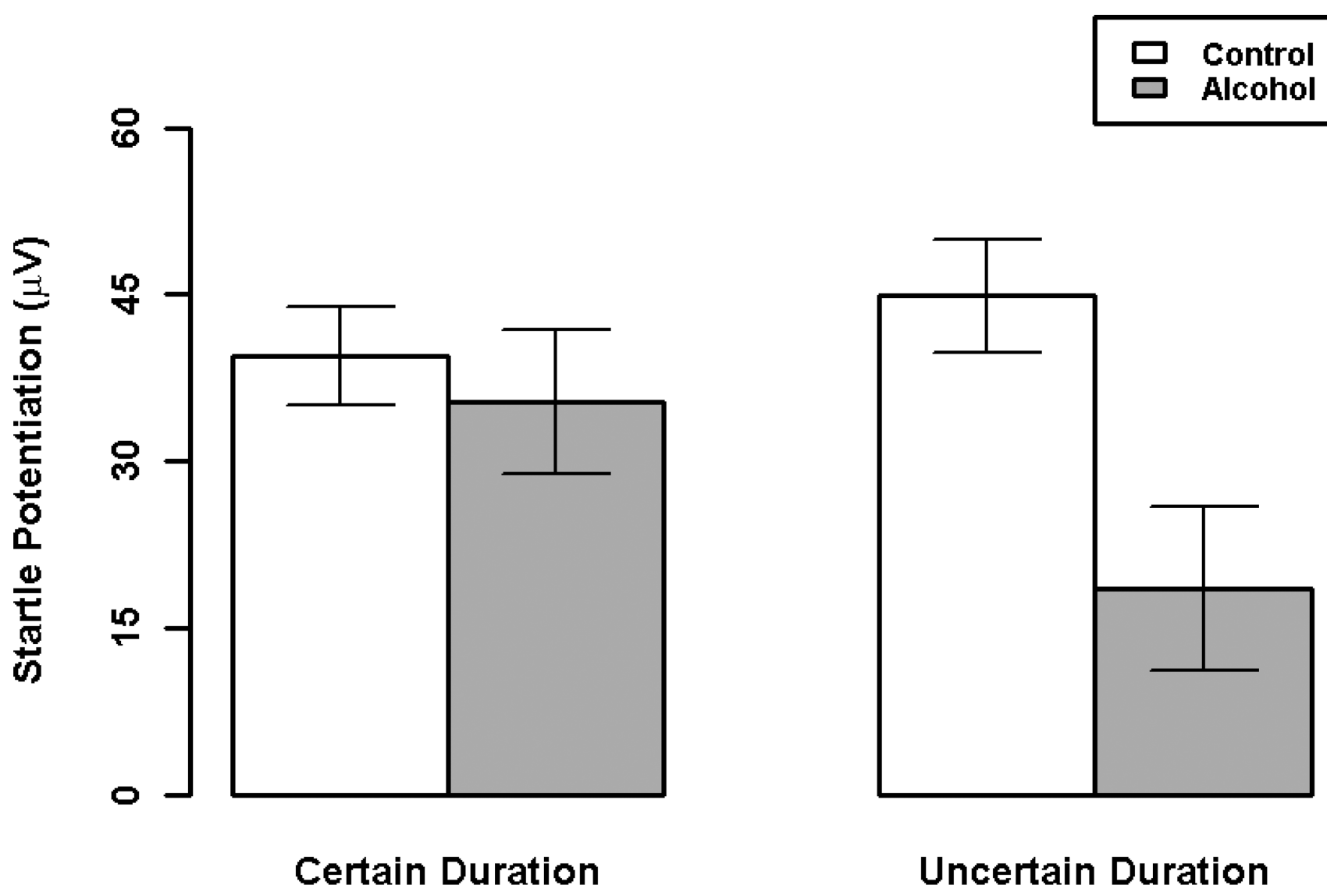

\section{Cue Type}

Figure 1. Beverage Group and Threat Uncertainty Effects on Startle Potentiation Startle potentiation during shock cues are displayed by Cue Type (Certain vs. Uncertain Duration) for probes at 4.5 seconds. The Beverage Group X Cue Type interaction was significant $(\mathrm{p}<.001)$. Follow-up tests revealed a significant simple effect of Beverage Group during Uncertain Duration cues $(\mathrm{p}=0.005)$. Error bars represent the standard errors for the startle potentiation point estimates from the General Linear Model. 


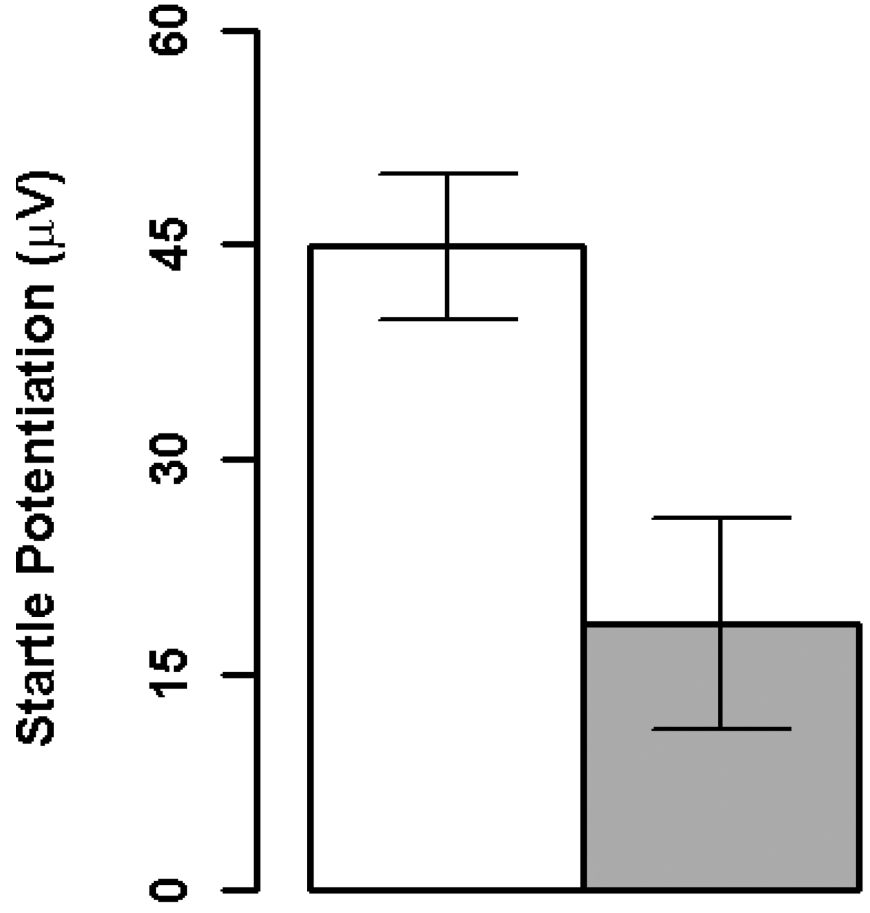

Early

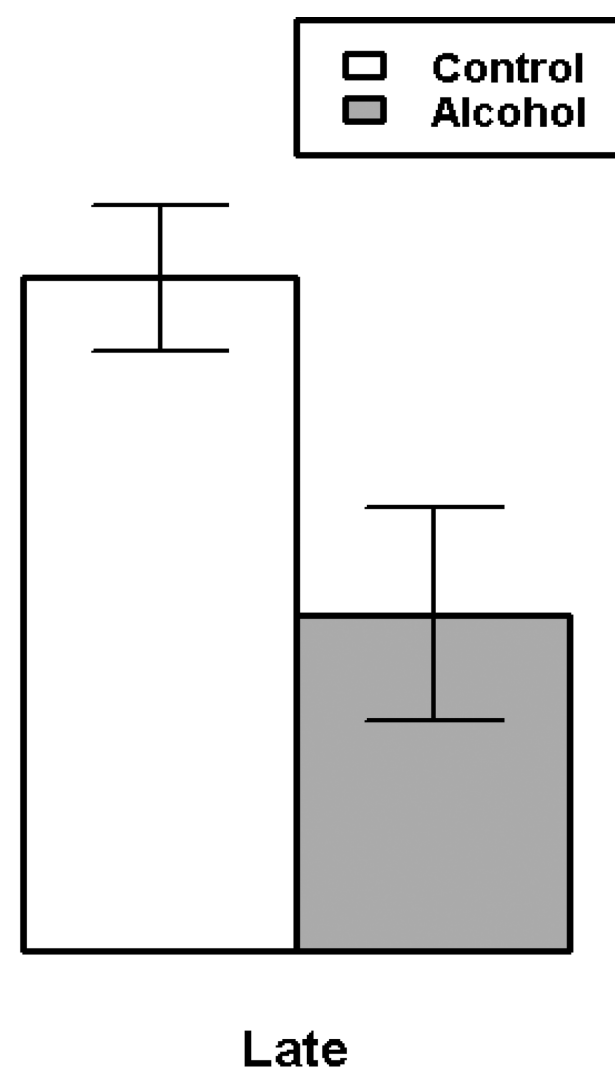

\section{Uncertain Duration Cue Probe Time}

Figure 2. Beverage Group Effect during Uncertain Duration Cue: Early vs. Late Probe Times Startle potentiation during Uncertain Duration threat cues are displayed by the probe time during the Uncertain Duration cues: Early (4.5 seconds) vs. Late (mean across 19.5, 49.5 and 79.5 second probe times). The Beverage Group X Probe Time interaction was not significant. Follow-up tests revealed a significant simple effect of Beverage Group during Uncertain Duration cues at later time points $(\mathrm{p}=0.012)$, indicating comparable alcohol SRD effects on startle potentiation at early (reported above) and later points. Error bars represent the standard errors for the startle potentiation point estimates from the General Linear Model 

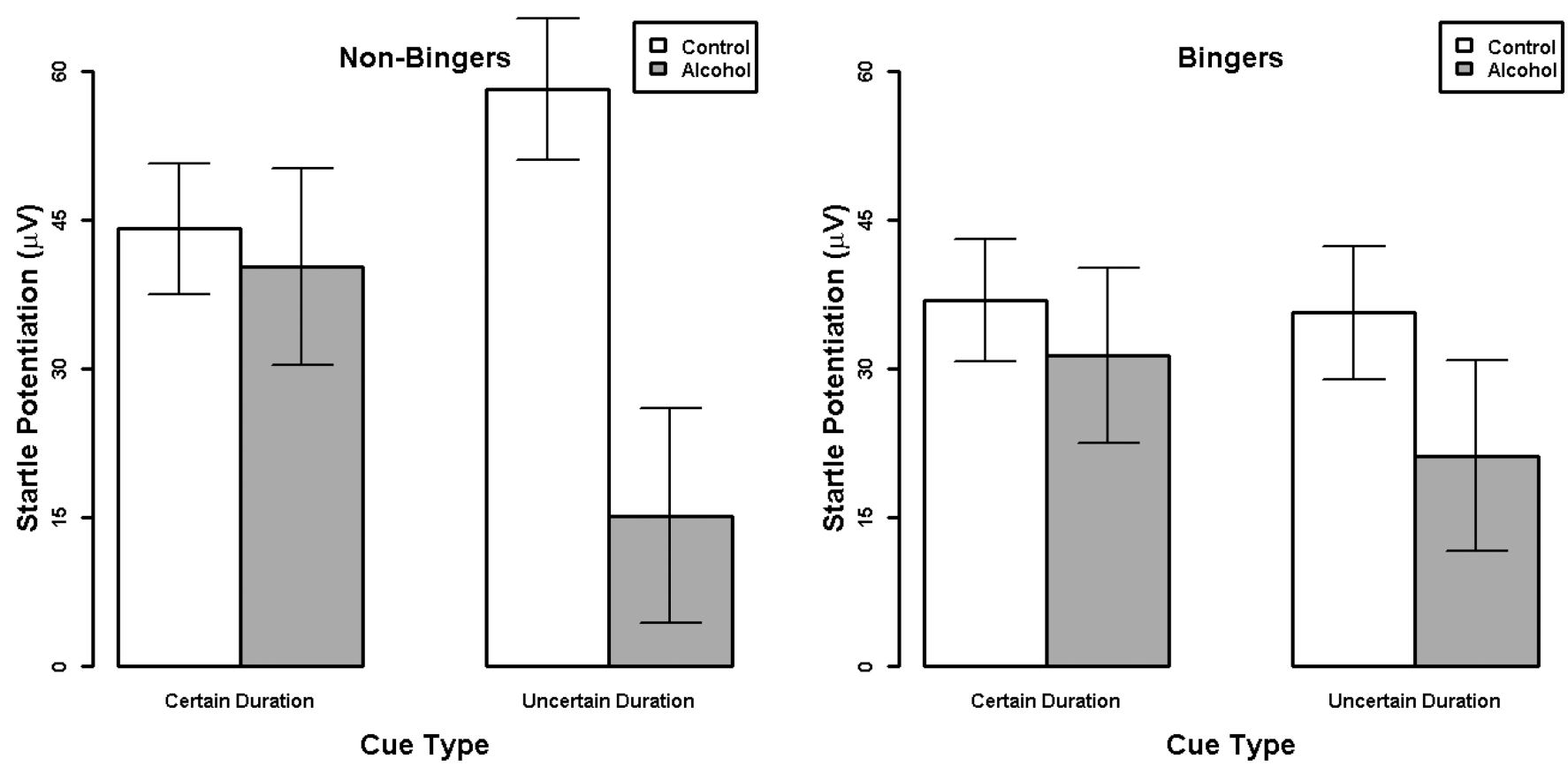

Figure 3. Binge Drinking status Moderates the Beverage Group X Cue Type Effect Startle potentiation is displayed by Beverage Group and Binge Drinking Status during Certain and Uncertain Duration cues for probes at 4.5 seconds. Error bars represent confidence intervals $( \pm 1 \mathrm{SE})$ for startle potentiation point estimates. 

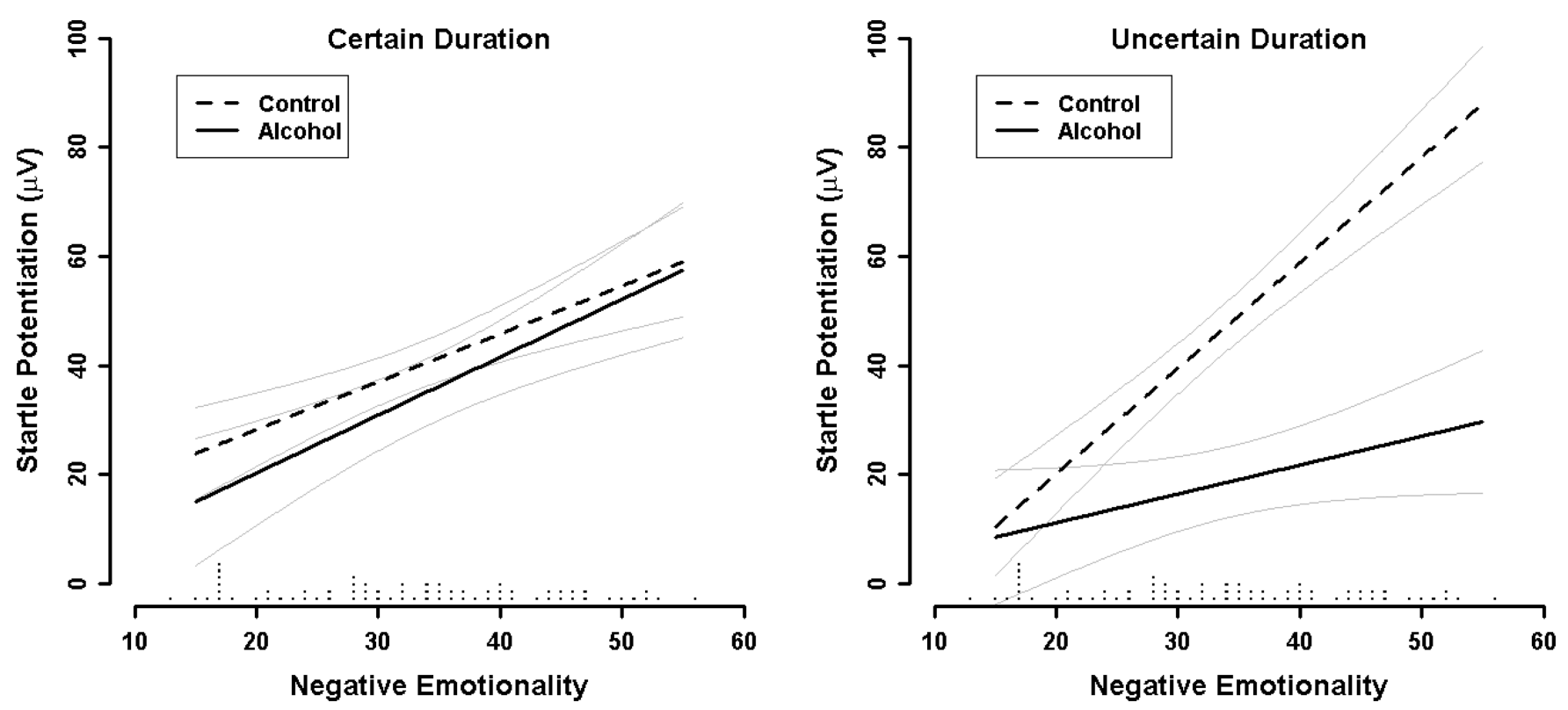

Figure 4. Negative Emotionality Moderates Beverage Group X Cue Type Effect

Startle potentiation is displayed by Beverage Group and Negative Emotionality during

Certain and Uncertain Duration cues for probes at 4.5 seconds. Confidence interval bands $( \pm$

$1 \mathrm{SE}$ ) for startle potentiation point estimates are displayed in gray. A strip chart on the $\mathrm{x}$-axis displays the distribution of scores for Negative Emotionality in the sample. 


\section{Table 1}

\section{Descriptive Statistics by Beverage Group}

\begin{tabular}{|c|c|c|c|c|}
\hline Measure & Alcohol & No-Alcohol & Placebo & p-value \\
\hline Total N & 24 & 24 & 24 & \\
\hline Female N & 12 & 12 & 12 & \\
\hline Age & $21.7(1.2)$ & $21.6(1.0)$ & $21.5(0.7)$ & 0.734 \\
\hline \multicolumn{5}{|l|}{ Alcohol Use and Problems } \\
\hline Drinks/Week $^{a}$ & $10.1(8.7)$ & $10.8(8.2)$ & $14.4(11.1)$ & 0.226 \\
\hline Binge drinker $(\%)^{a}$ & $54.2 \%$ & $34.8 \%$ & $70.8 \%$ & $0.046^{*}$ \\
\hline YAAPS & $5.3(2.6)$ & $5.2(2.9)$ & $6.2(3.6)$ & 0.475 \\
\hline SMAST & $0.7(0.9)$ & $1.1(2.1)$ & $0.9(1.2)$ & 0.631 \\
\hline \multicolumn{5}{|c|}{ Brief Multidimensional Personality Questionnaire $b$} \\
\hline Positive Emotionality & $78.5(15.0)$ & $77.5(12.7)$ & $78.7(11.2)$ & 0.940 \\
\hline Negative Emotionality & $34.3(13.0)$ & $35.0(8.1)$ & $30.1(12.1)$ & 0.271 \\
\hline Constraint & $70.5(16.4)$ & $69.5(14.6)$ & $67.7(13.2)$ & 0.809 \\
\hline \multicolumn{5}{|c|}{ Blood Alcohol Concentrations (BAC) } \\
\hline Pre-task BAC & $0.064(.011)$ & & & \\
\hline Post-task BAC & $0.067(.011)$ & & & \\
\hline Peak BAC & $0.071(.010)$ & & & \\
\hline
\end{tabular}

NOTES: Table contains group means with standard deviations in parentheses unless otherwise indicated.

YAAPS: Young Adult Alcohol Problems Scale past year problems. SMAST: Short Michigan Alcohol Screening Test

$a_{\mathrm{N}=71}$ due to invalid data for one participant in the No-Alcohol group

${ }^{b}$ Means (SDs) from the normative sample (Patrick, Curtin, \& Tellegen, 2002) for the broad trait scales of the Brief Multidimensional Personality Questionnaire are as follows: Positive Emotionality: 67.6 (14.7); Negative Emotionality: 34.9 (14.6); Constraint: 85.3 (14.5). 